\title{
A Constant Power Generation of Solar Photo Voltaic Systems using Mppt with Fuzzy Logic Controler
}

\author{
Pasala Gopi, P.Suresh Babu, V.Subhashini
}

\begin{abstract}
MPPT and furthermore CPG that utilizations fluffy rationale controller calculation. The Fuzzy rationale controller, By managing by method for nonlinear positions, suggest a predominant controller for these sort of associations. The method additionally profits by the explain and way to deal with the difficulty that conquers the multifaceted nature in demonstrating nonlinear frameworks. You can arrive at this objective, a MPPT and CPG model having A SOLAR module, The DC-DC converter (CHOPER), another fluffy rationale controller was created. Contemplating a buck converter and lift converter and furthermore buck-support converter highlights was done so as to recognize the most reasonable topology. An unsegregated sort of the sun oriented PV module distinguished converter was recreated and the outcomes used to fathom the master thoughts require to create and strain a fluffy rationale controller. wooly controller was coded as a continuous run program and the MPPT and CPG executed utilizing a dc-dc converter (CHOPER) constrained by a microcomputer. This outcomes can diminishing quality for the move of a photovoltaic power framework batteries can be completely energized and utilized during times of little astrophysical radiation.50KVA model was executed at $1 \mathrm{KVA}$. Testing indicated efficiencies above $95.5 \%$ complete dead from power transformation, fluffy rationale MPPT and CPG, and estimation and control hardware.
\end{abstract} controller, maximum power point following (MPPT), micro grid, chopper's, photovoltaic's, total harmonic demodulation (THD), A Constant Power Generation (CPG).

\section{INTRODUCTION}

Within this photo voltaic system the VI-features and output power of solar strings with changes in a solar irradiance, temperature and ripen Accordingly, The maximum power point tracking (MPPT) plan is implemented the requests increasing the removed charge from the given PV system and improving a total charge conversion quality. Different Types of MPPT algorithms, increasing in reach and difficulty, has been found the read and write Each method have been different merits and demerits in different types like computational quality of efficient, increasing the speed of detecting a maximum power point (mppt), operation under half Changing and also power oscillations during steady-state condition.

Photovoltaic cluster framework is likely perceived and generally used to the cutting edge in electrical power uses.

Pasala Gopi, Dep.of.Electrical Engineering, AITS Rajampet, Kadapa, Andhra Pradesh,India.

(E-mail: pasala.epe07@gmail.com)

P.Suresh Babu, Dep.of.Electrical Engineering, AITS Rajampet, Kadapa, Andhra Pradesh, India.

(E-mail: sureshram48@gmail.com)

V.Subhashini, Dep.of.Electrical Engineering, AITS Rajampet, Kadapa, Andhra Pradesh, India.

(E-mail: vallepusubhashini@gmail.com)
Keywords- Boost converter, buck converter, fuzzy logic

Revised Manuscript Received on September 10, 2019.

We create strait flow power without ecological effect of pollution. An among the growth in power generated products, the vitality through the Photovoltaic (PV) impact can be viewed as the most fundamental and essential manageable asset on account of the bounty, and maintainability of sun oriented brilliant vitality. For the most part sun based power age comprises a solar cluster, the dcdc converter and also an inverter. The maximum power of a solar PV module can supply is providing the product of the current and voltage of a maximum power point (MPP), Depends on the varying temperature in solar irradiance. The total short-circuit current of solar module is indirectly inversely proportional of photovoltaic irradiance, reducing considerably as the irradiation reducing, the open circuit voltage varies step by step changes an irradiation. The voltage reduces considerably when the temperature increases, a short circuit current growing.

In layout, increases in sun based brightening produce augments in the short out current, while augments in temperature decay the open circuit voltage, which impacts the yield power of the PV module. This changeability of the yield power suggests that without a coupling device between daylight based PV module and weight; the system doesn't work the most outrageous power point (MPP). the structure and showing a fleecy reason controller perceiving the most outrageous power point in sun based PV module, using the characteristics of fluffy method of reasoning to address an issue through etymological verbalizations. This paper tells interest usage of the numerical sort suggested in for showing of the sun based PV module, which is hate diode ward models, simply use to process the twist fitting parameter. The results were differentiated and the $\mathrm{P}$ and $\mathrm{O}$ controller which showed that the proposed technique presents less imperativeness disasters and certifications MPP in all cases surveyed in entertainment. It justifies referencing that this work is a bit of as a great deal of astute control techniques being surveyed in the assessment social affair was use a MPPT controller and CPG of negligible exertion and high profitability.

Hence, a general and adaptable calculation that accomplishes CPG was quick and dynamic outcomes and furthermore low control swaying during consistent state is fundamental for every single diverse topology of PVPPs. Absolute structures of the lattice associated PVPPs are one and two phase control transformation topologies, as portrayed. PWM control is given in order to coordinate the voltage of the lift converter. 
By then dc voltage open at terminals of the battery is changes more than $98 \mathrm{~V}$ dc voltage in to $230 \mathrm{~V}$ cooling voltage which is immediately open for private weights without using any transformer. So by using this strategy it decreases the cost of the general structure similarly as an extended capability. This lift inverter gives current sinusoidal waveform and prepared to pass on essentialness with low music. Along these lines PV control structure is arranged, exhibited and reenacted with resistive, inductive, and single stage selection motor burden. Hard and fast symphonious bowing moreover diminishes favored range.

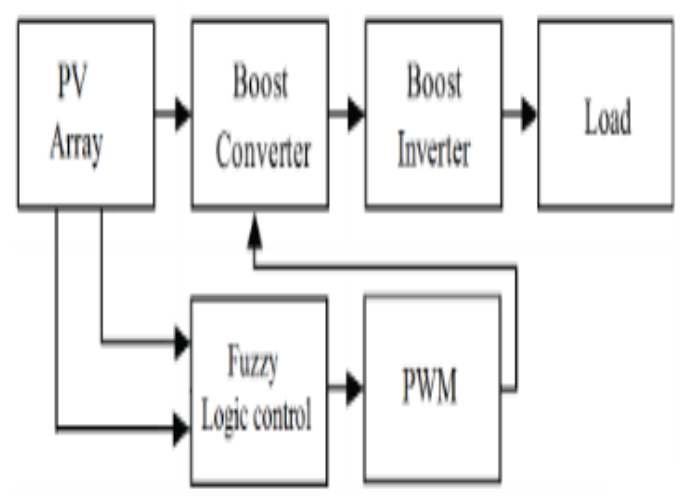

Fig Basic proposed system

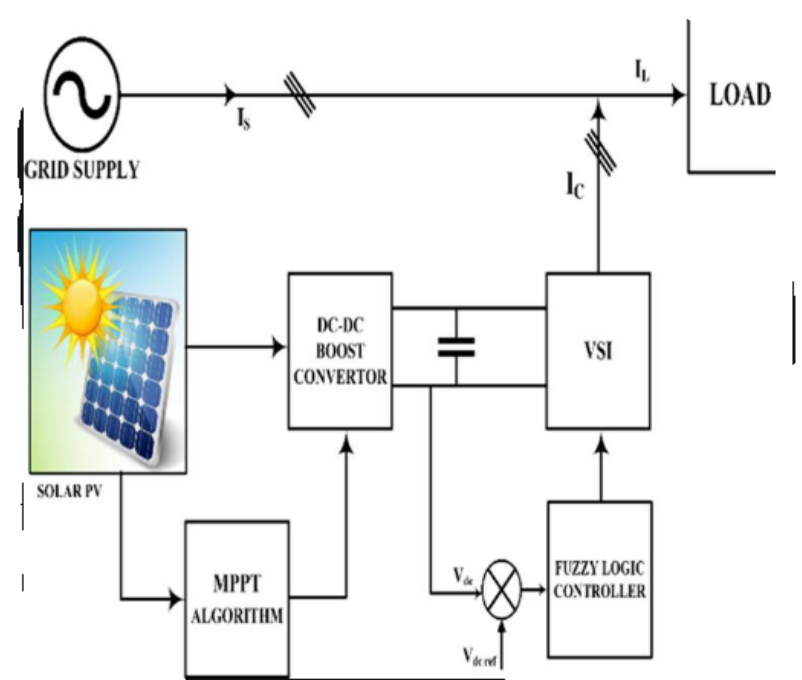

Fig Proposed System Block Diagram

\section{PREVIOUS WORKS}

In CPG for variable topologies of pvs. The meters of a CPG are exhibited the thoughtfulness on quality issues upkeep costs of PVPPs with variable yield voltage. This executed solitary composes PVPP. With the ability to control the yield dynamic power of the structure related inverter to system necessities.

Eliminate the referenced burden, two-orchestrate PVPP topology in with the strength to reach CPG action voltage disrupting impacts. A action forgetting about MPPT and CPG short circuit current control is moreover realized on the interleaved $\mathrm{dc}-\mathrm{dc}$ converter. As indicated by the powervoltage $(\mathrm{P}-\mathrm{V})$ properties of solar PV board is detecticting the counts of a voltage increase reference of CPG development the two-arrange PVPP is investigated In this methodology, reinforced to a dc-cooling help inverter. This inverter

the execution of the CPG figuring doesn't require any adjustment in the controller of the dc-dc converter.

In like manner, the action in a sun arranged PV board past the open hover circuit in voltage in sun dependent on PV board during quick changes irradiance, the action clarification at the back the PV board is moved to left $50 \%$ of the MPP obliges its uses only for two PVPPs. Thusly,One condition for a general estimation of intensity expansion reference of sun controlled PV board during CPG progression, which can be used for both single-and twocreate PVPPs during cross zone voltage irritating impacts or standard action.

The hysteresis band controller is indicates to change the execution of the calculation (time-step) and voltage increase between back to back successively focuses (voltage-step) in a smart stand-out answer and low control vacillating the intrepid state activity of the controller. The perfection along with adaptability of the proposed calculations are overviewed utilizing preoccupation and test underwriting on special PVPP topologies in like manner, exceptional irradiance of power reference turns.

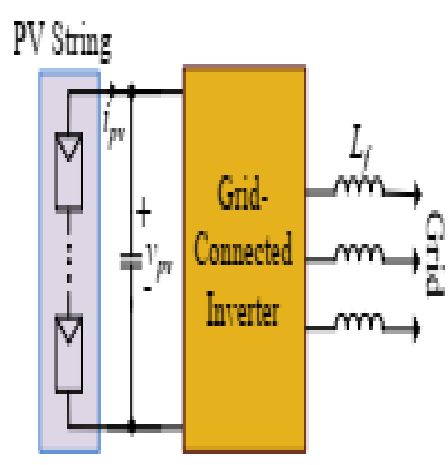

Fig structure Of Single-stage power conversion

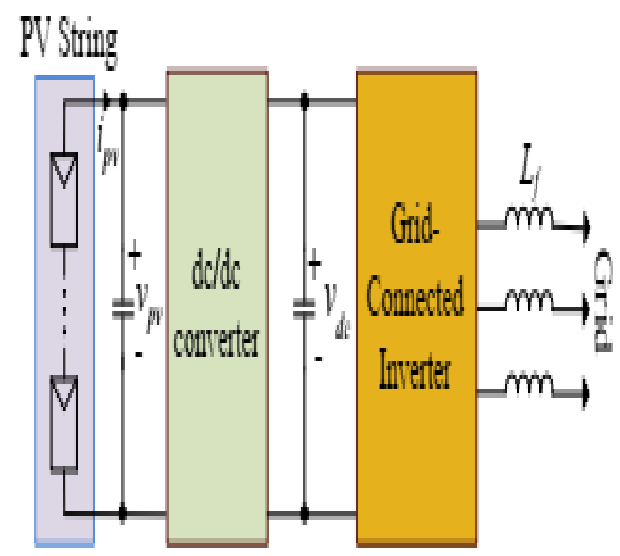

Fig structure of Two-stage power conversion.

\section{PROPOSED WORK}

A sun oriented PV control age framework appeared for an independent little private burden is structured, displayed and mimicked utilizing MATLAB/SIMULINK. The demand voltage from the PV demonstrate is given to the elevate dc-

Published By: 
dc converter which lifts the demand voltage of solar PV board put on display just as it manages its stipulate voltage free of the variety in sun oriented radiation and excitement by utilizing Fuzzy rationale controller. Also, this is plan to run dc-dc converter with PWM control method.In many applications, the PV cluster goes about as a power source to invigorate gadgets fit for putting away power. The limit of sun powered age frameworks depends vigorously on the nearness of light.

During the evening, a current may well stream again into PV cells on or after the bring. Switch current must put away on the justification that it causes spillage calamity, broad harm or could even reason a flame. Jamming diode is viable to avert switch current torrent. In the might of blocking diodes, the lift converter topology demonstrates significant favorable state of affairs over the buck converter.

Out the lift converter topology, the freewheeling diode fills in as the blocking diode to move away the turnaround current. Self-regulating of variety in rays based energy and warmth, the skeleton ought to time and again follow most extreme capacity to make the framework progressively effective. As the photovoltaic being irregular wellspring of intensity, can't fulfill burden need all the time.

The proposed power age is relevant to single stage private burden and single stage acceptance engine. Acquired demand voltage and current waveform of proposed framework appeared in Fig. Point by point examination is exhibited in consequent areas.

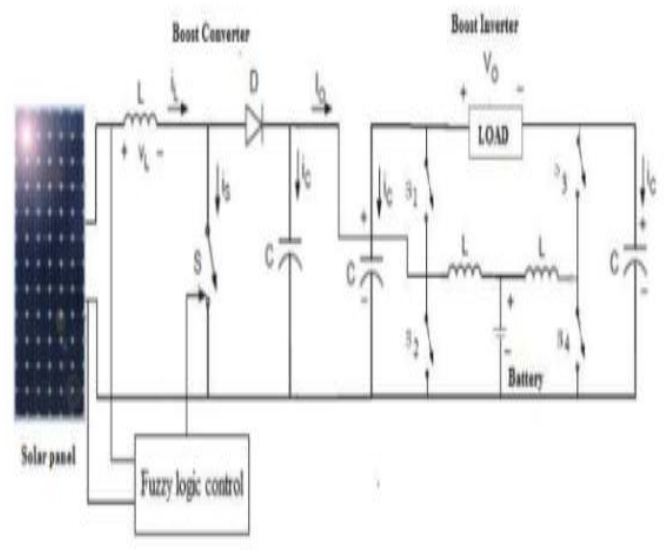

Fig Block diagram of pv system

\section{Fuzzy Controller Design}

Fuzzy control is a strategy that permits the development of nonlinear controllers from heuristic data that originates from the learning of a specialist. The fuzzification square is in charge of handling the info flag and allots them a fuzzy worth. The arrangement of guidelines permits a semantic portrayal of the factors to be controlled and depends on the learning of the procedure. The surmising system is in charge of making an understanding of the guidelines and their participation capacities. With the defuzzification hinder, the fuzzy data originating from the deduction component is changed over into non-fluffy data that is valuable for the procedure to be controlled.

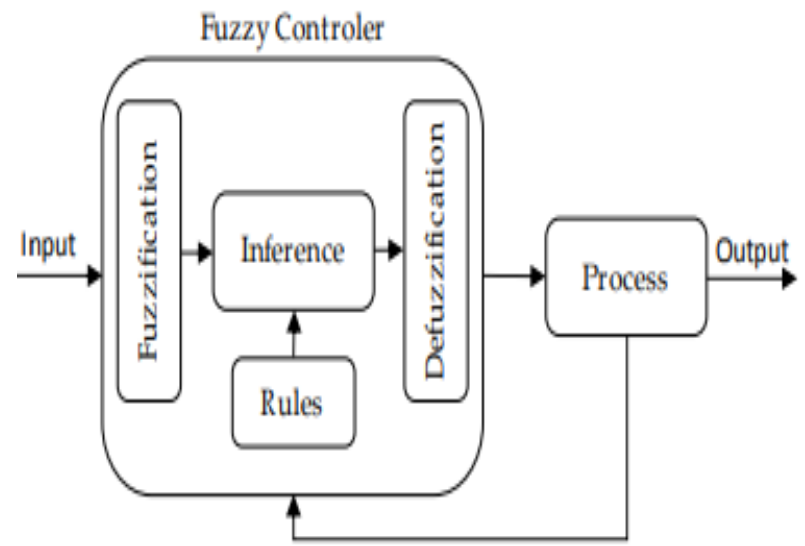

Fig Block diagram of the fuzzy controller.

\section{Fuzzy logic Controller Modeling:}

The controller was demonstrated with the MATLAB Fuzzy Logic Toolbox (Math Works, Natick, MA, USA). A Madman controller with the centroid defuzzification strategy was utilized. This technique was done utilizing a fuzzy controller derivation framework supervisor (FIS proofreader) (Math Works, Natick, MA, USA). the controller displayed in Simulink, for which a subsystem was performed to figure $\Delta \mathrm{V}$ and $\Delta \mathrm{P}$ so as to get the sources of info $\mathrm{E}$ and $\Delta \mathrm{E}$.
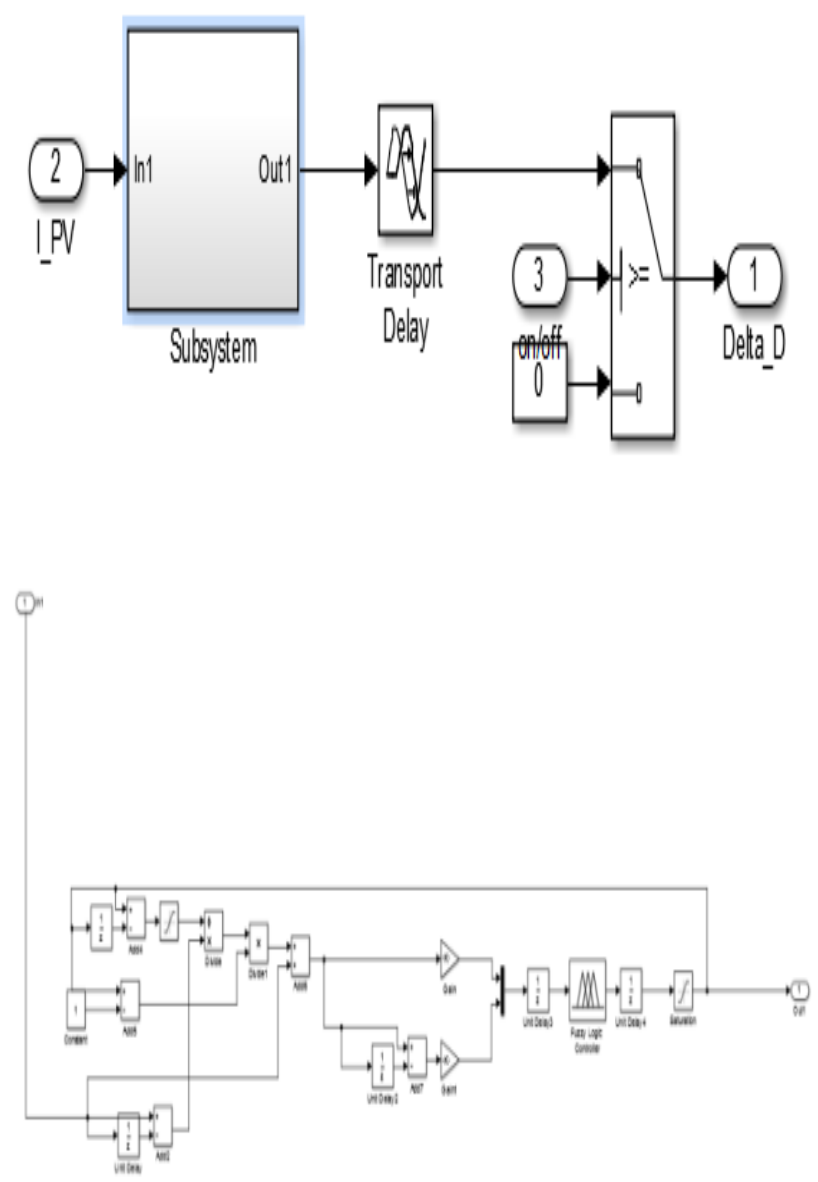

Fig Fuzzy logic controller 


\section{SIMULATION RESULTS}

The fragment estimations of inductors, capacitors are gotten from the arrangement and adjusted reliant on diversion results. The old test of the all out system is finished in MATLAB/SIMULINK.Programming situation. Resistive (R), inductive, non direct type loads and single stage enrollment motor weight are considered for the assessment as a withdrew action of sun arranged photovoltaic structure with the proposed system. The yield waveform of proposed circuit is showed up in Figure. After separated, Total Harmonic Distortion of the proposed system offers $1.56 \%$ to resistive weight showed up and $6.83 \%$ for inductive weight showed up in Figure. This will give better money related and concentrated positive conditions. The reenactment results exhibit that this system can change the cushy parameters for snappy response, incredible, transient execution, heartless toward assortments in outside disrupting impacts.

This structure can outfit essentialness to an utility with low sounds. It is moreover obvious from the results that without a doubt the symphonious turning of the yield inverter current waveform at different sun situated board voltage levels can be kept up close the predefined rule cutoff purposes of the utility.

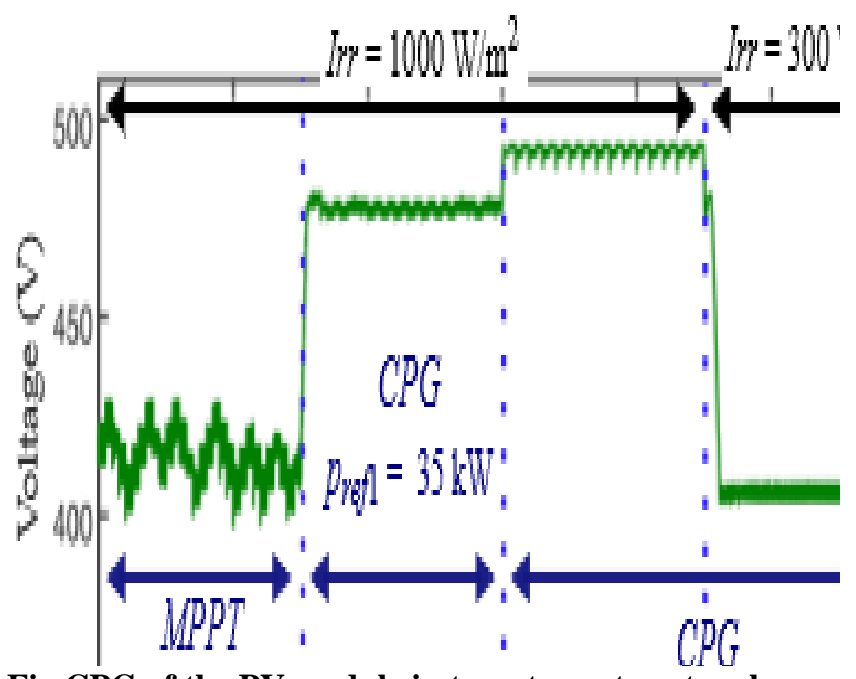

Fig CPG of the PV module in two stage-stage topology with the moment of voltage reference in right-side of MPP: $P V$ voltage $\left(V_{P V}\right)$

In this manner, the proposed computation extends/decreases the voltage reference in the right-/left$50 \%$ of MPP to Point $\mathrm{C}$ to change the PV board control with its reference regard. One of the charming features of the proposed estimation is its life for the movement in the right$50 \%$ of MPP, when its action point goes past the opencircuit voltage of the PV board. At $\mathrm{t}=9 \mathrm{~s}$, an unexpected reduction of the irradiance from $\operatorname{Irr}=1 \mathrm{~kW} / \mathrm{m} 2$ to $\mathrm{Irr}=$ $0.3 \mathrm{~kW} / \mathrm{m} 2$ is repeated

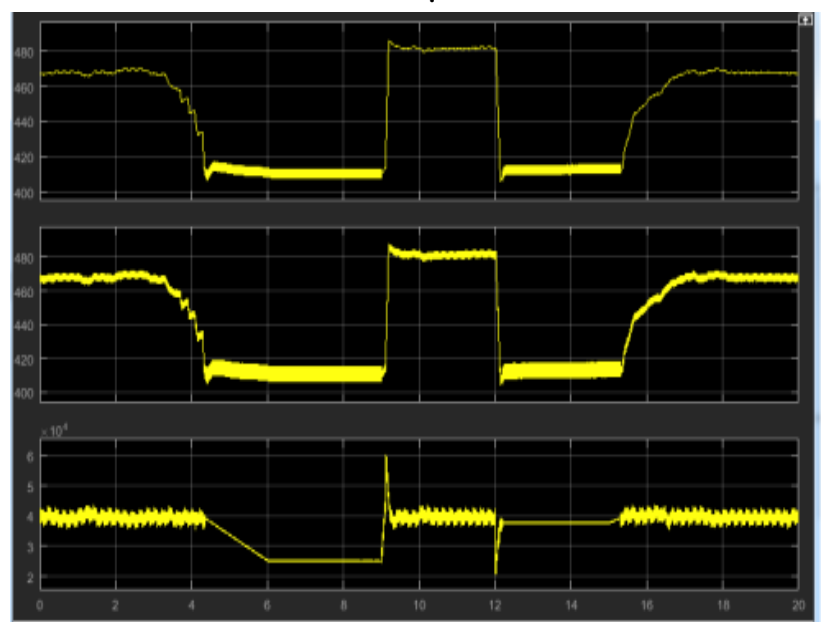

Fig even control age band of the PV component in the two-stage topology with the lobby group of the voltage allusion to the left-side of MPP:Voltage location (vref).

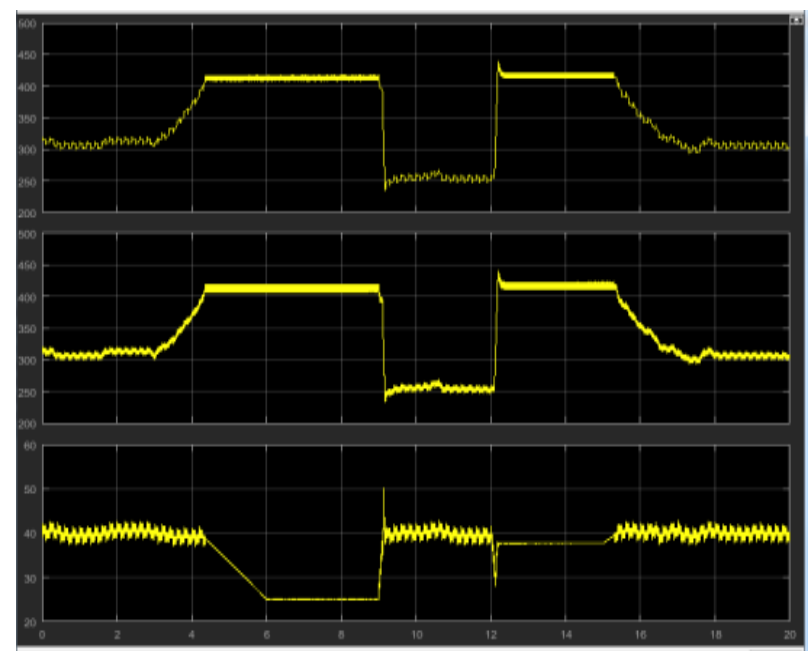

Fig unvarying influence age band of the PV module in the two-stage topology with the society of the energy situation to the left-side of MPP:extract power from the PV module (ppv)

the PV board experience little control wavering, as appeared in figure 11. The irradiance decline directly between $\mathrm{t}=3 \mathrm{~s}$ and $\mathrm{t}=6 \mathrm{~s}$, as delineated. then again, before $\mathrm{t}$ $=4 \mathrm{~s}$, the accessible standard is bigger than Pref and in this manner, ppv is managed at $40 \mathrm{~kW}$ by expanding vpv. It tends to be seen that during this transient period, little league step and enormous voltagestep is utilized which results in the quick powerful presentation of the proposed CPG calculation. Between $t=6 s$ and $t=9 s$, the PV string works at Point B, which is its greatest power point at Irr = $0.5 \mathrm{~kW} / \mathrm{m} 2$, on the grounds that the accessible power is littler than the required power. There is a stage increment of irradiance at $\mathrm{t}=9 \mathrm{~s}$ to $\mathrm{Irr}=1.2 \mathrm{~kW} / \mathrm{m} 2$, which accordingly the activity point is immediately moved to Point $\mathrm{C}$ in figure 12 with a diminishing of the voltage to $\mathrm{vpv}=250 \mathrm{~V}$. Essentially, a stage decline in the irradiance happens at $\mathrm{t}=$ $12 \mathrm{~s}$ to $\operatorname{Irr}=0.75 \mathrm{~kW} / \mathrm{m} 2$ that moves the activity point to $\mathrm{D}$.

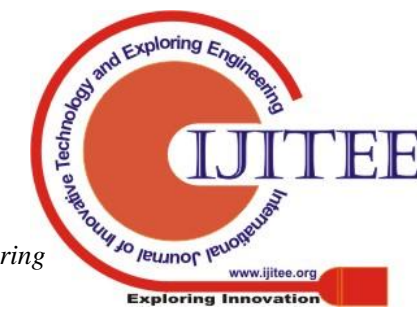




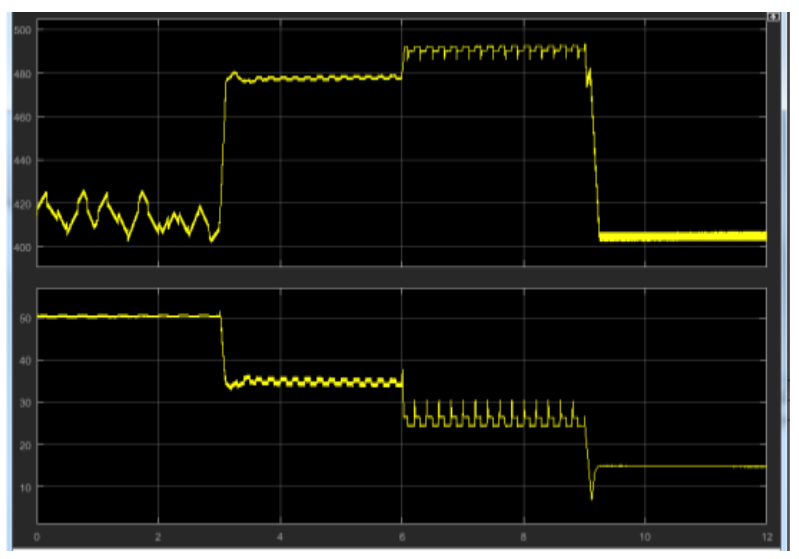

Fig even supremacy age band of the PV module in the single-stage topology through the lobby group of the current location to the right-side of MPP: extract influence from the PV part (ppv)

The activity of the projected CPG calculation with the advance of the activity point to right-half of MPP is analyzed under the irradiance profile appeared outer on behalf of a solitary stage PVPP with lattice associated inverter and results are delineated in figure 14. meant for this situation study, the quantity of arrangement associated PV board in the PV string is expanded to 25 so as to accomplish the required dc-interface voltage for matrix association. Under Irr $=1 \mathrm{~kW} / \mathrm{m} 2$ (before $\mathrm{t}=3 \mathrm{~s}$ ) the proposed calculation directs the dc-connect voltage to vs.(peak ) In this conduct the activity point is stirred to Point $\mathrm{B}$, which is the most excessive power purpose of the PV board Irr $=0.5 \mathrm{~kW} / \mathrm{m} 2$ and intensity of around $25 \mathrm{~kW}$. The test situation takings with comparative and the introduced outcome show the facility of the proposed CPG calculation in direct the yield influence of the singlestage PVPP to the required power reference.

\section{CONCLUSION}

This proposed plan has been discovered conservative and effective change framework for changing over the demand the dc voltage PV solar exhibit air conditioning $230 \mathrm{~V}$ rms. The yield intensity of sunlight based PV control age framework is utilized to sustain a solitary stage private burden at $230 \mathrm{~V}$ and furthermore single stage acceptance engine, a canny control procedure utilizing fuzzy logic control is related to a MPPT and CPG controller so as to improve vitality transformation proficiency. The lift inverter utilized here has conservative just as specialized favorable circumstances over customary voltage source inverter. Reproduction results on various burdens are well inside THD satisfactory range. This proposed strategy has a few highlights, for example, it lessens the expense of the general framework, minimal size just as an expanded effectiveness in photovoltaic system.

\section{REFERENCES}

1) Al-Nema.M.A. Mr.Shamil and M.Al-Layla,"Analysis, Design and usage of adjusted single stage inverter", IEEE Trans. on Power Electronics, Vol. 19, pp. 1184-1194, July 2007.

2) Huan-Liang Tsai, Ci-Siang Tu, and Yi-Jie Su, "Improvement of Generalized Photovoltaic Model Using
MATLAB/SIMULINK", Proceedings of the World Congress on Engineering and Computer Science, October 2008.

3) R. O. Caceres and I. Barbi, "A lift dc-air conditioning converter: investigation, structure, and experimentation," IEEE Trans. Power Electron., vol. 14, no. 1, pp. 134 141, Jan. 1999.

4) Kirubakaran.A, Shailendra Jain, and R. K. Nema, "DSP Controlled DC/DC Boost Converter for Renewable/Green Power Applications", IEEE Power and Power India Conf., pp. 1-6, November 2010.

5) H. Renaudineau, F. Donatantonio, J. Fontchastagner, G. Petrone, G. Spagnuolo, J. P. Martin, and S. Pierfederici, "A PSO-based worldwide MPPT method for circulated PV control age," IEEE Trans. Ind. Electron., vol. 62, no. 2, pp. 1047-1058, Feb. 2015.

6) M. Rica, P. Manganiello, E. Monmasson, G. Supporter, and G. Spagnuolo, "FPGA-based usage of double Kaman channel for PV MPPT applications," IEEE Trans. Ind. Informat., vol. PP, no. 99, pp. 1-1, 2015. 